\title{
EVOLUTIONARY HERMENEUTICS: \\ DOGMATIC IMPOSITION OR BIBLICAL DISCERNMENT? A REJOINDER
}

\author{
Klaus Nürnberger \\ School of Theology \\ University of Kwa-Zulu Natal
}

\begin{abstract}
This essay responds to five reviews of my Theology of the Biblical Witness. While the project was generally appreciated, there was a general feeling that I imposed a pre-formulated grid on the wealth of the biblical detail. In my response, I argue that, to reduce unmanageable complexities, research cannot do without models. While deductive models are impositions of systems of inferences from ostensibly selfevident assumptions, inductive models are obtained from prioritisation of aspects of experienced reality. Moreover, in their verdict of linearity, reductionism and grid imposition, the reviewers have applied their preconceived concepts of evolution rather than taking heed of the model that I have actually utilised. Here evolution is seen in the context of the cosmic entropic process and take levels of emergence into account that covers the whole of reality. To evaluate the model, the actual procedures and findings of my research must be checked against the biblical material. I claim that my method is more capable of integrating biblical research and theological reflection than conventional approaches.
\end{abstract}

Key words: Biblical Theology, K Nürnberger, Soteriology, Systematic Theology

\section{Introduction}

I would like to thank my colleagues for the effort invested in reviewing such a hefty volume. I am also grateful for the opportunity to respond. The space allocated to my response is circumscribed and I can only deal with a few prominent issues. To honour their work, and to widen the scope of the discussion, I include some comments made by Biblical scholars in pre-publication assessments, although these are not published.

I am thrilled by the positive comments made. Some are deeply empathetic. Some praise the novelty, comprehensiveness, clarity, and consistency of the argument - in spite of substantial disagreements in some of the detail. Some appreciated the dynamic and situational approach to the biblical witness. One commentator felt that the need-response dialectic was "excellently capable of giving space to contextual and time bound theological and social-ethical approaches" (Gerstenberger).

Well done, Klaus, I could have said to myself, if not...! The five reviewers more or less agree that, in spite of its admirable intentions, my project has essentially failed because I fell into the very trap that I wished to avoid: Imposing pre-conceived linear grids on the biblical material, thus making my argument circular and self-defeating (Jonker, Punt, Conradie). It is important for me to understand in which sense, and to what extent, this verdict may be justified. I will unpack it stage-by-stage, referring to the reviews in brackets or footnotes. 


\section{Professional Deficiencies}

This topic can be disposed of most easily. I readily concede that, as an amateur in Biblical Studies and hermeneutics, I cannot possibly reach the level of expertise expected from a professional. All commentators, even the most positive, remarked that they would disagree with many of the detailed statements in the book.

Given the chaotic situation within the discipline itself, that is hardly surprising. I have gleaned the bulk of my material, after all, from within the discipline. ${ }^{1}$ But that is no excuse for shoddy work that I may have become guilty of. In many cases, I suspect, I may have deserved a thrashing. Of course, in such cases I would have to be convinced that I was wrong. ${ }^{2}$

\section{The Formal Relationship Between the Five Kinds of Reading}

This is the first major area of confusion. No fixed boundaries between the five approaches were ever intended. Nor was any one of them disqualified in principle. I only highlighted the problems of each (p 42ff), including my own (p 94ff). Let me sketch the relationship between them and my own proposal.

Before-the-text reading is an immediate response to an existential situation of need within its overall social, cultural and spiritual contexts. ${ }^{3}$ Luther's quest for a "gracious God" in the face of the last judgment, and the quest for liberation of the poor and oppressed in liberation theology are well known examples. But even the metaphysical formulations of classical theology have once been responses to needs caused by a demanding Hellenistic environment.

I have stated that this kind of reading is ubiquitous in biblical history itself and inescapable for us today. I did not "fail to admit to contextuality" (Punt), but stated clearly that my own approach is a response to the needs we face in the 21 st century (ch 1). ${ }^{4}$ This is not a circular argument, but an affirmation of the need-response principle. My below-thetext reading, while not being "distinctly different" (Conradie), is characterised by its wide historical scope, its orientation towards the vision of comprehensive well-being and its dynamism, all of which are not characteristic of simple before-the-text readings.

When such responses to situational needs are dogmatised and elevated to the status of timeless criteria of truth and applied to the scriptures, we have above-the-text reading.

For instance, the chapter on the exodus (where Lawrie and Wittenberg suspect polemical intentions) was inspired by the work of Jon Levenson (1996), certainly a prominent Jewish scholar. I have explicitly endorsed the liberationist agenda as such here (2002:196ff) and in "Subscribing to confessional documents today" (Nürnberger 1991). It is their use of scripture that I put under the spotlight. Similarly, the close link between exodus and conquest, and the treatment of covenant and law as a separate tradition, was inspired by Von Rad's work on Deut 26:5ff, which may now be obsolete. But if the entire package is deuteronomic and most other sources are post-deuteronomic, as is now widely assumed, my argument that the tradition itself has linked the two motifs is still valid.

2 For instance, I accept Lawrie's comment on my use of Dt 13:1-5. I never meant to place Deuteronomy and the priestly traditions into the same folder. They are obviously far apart both in terms of time and theology. But it takes an awful amount of creative imagination to perceive the exodus to be a determinative literary motif in Deutero-Isaiah (Lawrie and others). While there are a few allusions to this tradition here and there (e.g. Is 43:2f,16, where he bids his listeners to forget the past), Dt-Is announces Yahweh's sovereign act of creation to reconstitute Israel's integrity around Mount Zion and Jerusalem by humiliating Babylon and bringing back the dispersed.

3 I accept that that the conventional term "in front of the text" would have been more appropriate (Conradie, West, Wittenberg) for some cases. In-front-of-the-text readers presumably allow the text to speak to them with authority. However, the term "before the text" suggests that they already know what they want the text to say.

$4 \quad$ I have never said that a text has only one meaning, nor have I denied that polysemy is necessary and inescapable, nor have I excluded metaphor and allegory in literature (Punt). My point is that not all readings are equally appropriate. 
Above-the-text reading ignores the phenomenon that I described in my "threshold theory" of needs, namely that needs gain and lose priority status over time due to changing situations ( $\mathrm{p} \mathrm{10)}$. Both before-the-text and above-the-text readings can be ideologically motivated (cf Jonker), but they do not have to be.

I have tried to avoid above-the-text reading, although most of my critics (Lawrie, Jonker, Conradie) believe that I have failed to do so. ${ }^{5}$ I will come back to that below. Here it suffices to say that, because it covers all kinds of needs when prioritised according to threshold theory, my approach is less prone than others to above-the-text reading as I have defined it. ${ }^{6}$ In my research I discovered that consistent behind-the-text reading exposes a series of before-the-text readings of inherited traditions by biblical believers and authors. Redemptive responses are evoked by all kinds of deficiencies in comprehensive well-being. My method of below-the-text reading thus depends on behind-the-text reading of historical

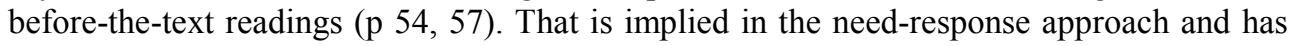
manifested itself in every one of my trajectories.

The rationale of below-the-text reading is to discover and define criteria for appropriate before-the-text-readings that are based on the dynamics of the biblical tradition itself. Not all before-the-text-reading can be considered acceptable. I have spelt out the criteria of what is acceptable by referring to the consequences of certain readings in terms of the infinitely flexible meta-norm of comprehensive well-being and its situational articulation in concrete deficiencies of need - which I gleaned from the biblical witness itself. ${ }^{7}$

In-the-text reading, as I use the term, is not the same as the detailed exegesis of particular texts, as some commentators (Lawrie) have misunderstood me. In-the-text reading assumes that the completed body of the canon is, as it stands, the Word of God for all people at all times and situations. Apparent diversities or seeming contradictions within the canon must be sorted out through inner-canonical explanation and harmonisation. Neither the history of a text, nor its "Wirkungsgeschichte", nor the presuppositions carried to the text by the reader, nor the needs of the reader are supposed to be of any consequence.

My historical approach precludes crude in-the-text reading as defined above. However, below-the-text reading and in-the-text reading share the assumption that the biblical tradition conveys the "Word of God". If these clarifications are acceptable to my critics, a lot of misunderstandings will have been cleared out of the way.

\section{Induction or Deduction?}

Now for the next step. In this book, I committed myself to induction (= an experiential approach) as opposed to deduction (= logical construction). Deduction derives inferences from ostensibly unassailable axioms. One can, for instance, define divinity in terms of omnipotence and omniscience and deduce predestination from these assumptions. Induction in hermeneutics, by contrast, tries to establish what kind of spiritual, cultural, social and

5 I agree with Jonker that to force a wrong calibre bullet into the barrel can backfire. The question is whether I have actually done that. His concern for somebody with the expertise to calibrate bullet and barrel has led me to dig deeper into the discipline than most other theologians - which shows my highest regard for this task.

6 How this all-inclusive meta-norm can possibly be reductionist (Jonker) escapes me.

7 Punt is certain that the soteriological urge (God's vision of comprehensive well-being and God's response to situational needs) as the "rationale" which leads the tradition in a particular direction is "formulated and not found!" As if something formulated cannot have been found! If it does not exist in the Bible, scrap all prophetic promises, priestly sacrifices, the healing miracles of Jesus, the whole of eschatology, including the kingdom of God and Rev 21f. That the history of the biblical canon was "chequered and intensely contested" I have shown on every page of Part II. 
environmental experiences have motivated biblical believers and authors to formulate certain texts, and certain readers to read certain texts in certain ways.

Empirical research and experiential analysis are both inductive, though the latter is much more inclusive than the former (cf Lawrie). I rejected empiricism only where it is inappropriate, that is, where modern readers assume that to be true, a biblical faith statement rendered in story form must have happened historically the way it is presented.

There is a legitimate use of deduction within the inductive methodology. Astronomers can explore interplanetary balances and deduce from their findings that there must be another planet, then train their telescopes on the calculated location and find the planet. Here a hypothesis deduced from inductive findings is verified by inductive methods.

I have stumbled across the repeated use of the royal-imperial paradigm in a variety of forms through much of the biblical literature and its ultimate inversion. This challenged me to look whether similar trajectories and inversions could be shown to exist within the evolving body of traditions and I found that they could. I presented my findings to my colleagues with the expectation that they would check whether these findings were valid. Some argue that they were not, so let us continue.

\section{Prioritisation or Imposition?}

Looking at the tiled wall of a bathroom, I discern vertical lines, horizontal lines, diagonal zigzags, crosses, squares, rectangles, tile sequences going up, or down, or across. All these "visions" are reflections of the objective pattern on the wall. What makes me "see" them is the mental prioritisation of certain networks of relationships at the expense of others.

Prioritisation is not the same as imposition. An imposition would be to draw concentric circles or intersecting ovals on the wall. I could have imposed the topoi of classical dogmatics on my biblical theology, for instance, beginning with the classical doctrine of God, which is gleaned from Greek metaphysics. There are such biblical theologies, some even written by biblical scholars.

While some argue that privileged perception is discriminatory and oppressive, prioritisation is an indispensable tool of the inductive approach. Whether you stain bacteria to make them visible, use spectral analysis to discover layers in the earths crust, or train your telescope on a galaxy, no science can do without it, nor can everyday life.

In short, the use of models or paradigms does not run counter to the inductive approach, but is an indispensable tool of inductive discernment. The question is not whether I was entitled to use a model in the book, but whether the model I used is appropriate to highlight particular aspects of the reality under review and what its limitations might be. Thus to the next step!

\section{Contours or Detail?}

As a space ship is launched, an astronaut notes a cluster of trees down below. The distance to the earth increases and the contours of the continent, then of the earth's crust, then of the planet as a whole become visible, but only at the expense of the contours of the cluster of trees. When a microbiologist probes into the organisms that populate the bark of the trees, the contours of reality become visible at another level, but again at the expense of the contours of the trees. At still "deeper" levels, a physicist may discover electrons or microparticles. In all these cases, the inductive method is used to investigate aspects of the same reality. The findings do not contradict, but complement each other. Insight at any level of 
investigation presupposes a drastic reduction in complexity without which the volume of information would become unmanageable.

Reflecting on the relation between systematic theology and biblical exegesis several commentators mentioned the difference between "thematic summation" and "detail of the text" (Brueggemann, Rohloff, Gerstenberger). If biblical studies, biblical theology and systematic theology were committed to induction, they could complement each other. Complementarity simply widens the horizons of knowledge in all directions.

Systematic theology tries to see the contours of the planet in the context of the contours of the galaxy. The real question is whether the astronaut has apparitions when he sees that the blue planet has a structured surface of oceans and continents or not. He can invite a nuclear physicist to check whether the contours he sees are those of continents or cloud formations.

I can similarly request my colleagues to check whether there is indeed an evolving current of meaning across vast stretches of biblical history or not. More specifically, I could ask whether I had apparitions when I saw an inversion of basic assumptions between dictatorship (Ps 2) and servanthood (Mk 10:35ff, Jn 13:1ff), between exclusion (Dt 7, Ex 23) and inclusion of outsiders (Eph 2:11ff), or between conditional acceptance (Dt 28) and unconditional acceptance (Eph 2:1ff, Lk 15:11ff). ${ }^{8}$

If the nuclear physicist then argues that the contours of the earth, as seen from the space ship, are an illusion because strictly speaking reality consists of nothing but the random movement of micro-particles, the astronaut will respect her expert opinion, but chuckle a bit over her preoccupation with a truism that obscures rather than reveals broader perspectives on reality. ${ }^{9}$

\section{Bridging the Abyss of Time}

The Bible was not written for the 21 st century. Our reality is subject to accelerating change. Lessing's "ghastly gully" between then and now has turned into a hurricane, and his "eternal truths of reason" into intellectual fossils (cf Lawrie). As I have shown (p 414ff), biblical paradigms of salvation no longer work for us very well, which is the reason why we have to go beyond biblical hermeneutics per se (cf Punt). We have to do for our times what the biblical authors did for theirs: Reformulate God's redemptive responses to contemporary needs in terms of contemporary frames of reference.

It is not our task to demarcate turfs for disciplines, therefore, but to get a job done. To be of practical use, theology must be an integrated process (demanded by Punt) that retrieves the thrust of the Word of God from its primal sources (Biblical Studies), reflects on its plausibility, consistency and relevance (Systematic Theology and Theological Ethics) and articulates it in forms which are accessible and relevant to believers and non-believers of today (Practical Theology). Anxieties that one of these disciplines might trespass onto

8 In their rejection of supersession, do Jonker and others want to suggest that it is immaterial whether leaders in church and society are authoritarian and oppressive, or facilitating and empowering? I do not scrap the early stages (Jonker) precisely because we have to undergo this transformation again and again.

9 I could here refer to various pronouncements of Punt: "elimination of the episodic", "harmonising and indifference to particular ...contexts", "return to imperialist designs", "paradigms eventually displacing the biblical materials", biblical "intricacies and complexities traded away for the spiritual ease-of-use", "particularities bundled together and sacrificed on the altar of a common approach", "paradigms obscuring / replacing texts", providing a "rewritten Bible", his fear that the Old Testament would become superfluous and the New Testament hamstrung, etc. 
the territory of the other, exercise dictatorial powers over the other, or be involved in selfaggrandisement at the expense of the other (Punt), are out of place. ${ }^{10}$

Alternatives to this integrated view of the theological enterprise are not necessarily convincing. The isolationist motto "live and let live" has led to the current gap between the disciplines. The distinction between descriptive and normative theology is questionable because the ideal of value-free analysis has proved to be deceptive and dangerous. If you condone slavery in "authoritative" texts, you have no authority to reject it today.

\section{A Complex or a Uni-linear Model? (Evolutionary Theory)}

Most reviewers believe that I have imposed a linear and one-dimensional model on the scriptural material, forcing its riches and pluriformity into a narrow conceptual straight jacket (Jonker, Field, Punt). Let us see how far this is true.

It is not my fault that physical time moves relentlessly in one direction; that events come in sequences and that previous stages impact later ones by simple cause and effect and collective mental conditioning. Inherited memories lead collective consciousness in certain grooves called traditions, which can be wide and diffuse, or more narrowly defined. ${ }^{11}$

That redemptive expectations gave the biblical faith an arrow towards the future from early times onward can hardly be disputed. Nor can it be disputed that later insights change or displace earlier insights and that, sometimes at least, there may be some progress in the acquisition of insight, thus "supersession". Alchemy has changed into chemistry, astrology into astronomy, and the ox wagon has been replaced with the diesel truck. We can ignore such facts for ideological reasons, claiming that all cultures and convictions are of equal beauty and dignity, but we cannot thereby remove them from reality.

However, the fact that time is sequential and irreversible, does not preclude the other fact that reality is a highly dynamic, multifaceted, multi-linear process in which everything is related to everything else in a complex, yet structured way. It is due to this complexity of reality that no academic discipline can operate without a set of assumptions, models, or paradigms. The question is not whether or not one is entitled to use models, but what such models reveal and what they conceal, in how far they reflect certain contours of reality and in how far they distort such contours.

The use of an evolutionary model was risky and I avoided it in the popular version of the book (Nürnberger 2004). The concept has a considerable history, a plethora of meanings and lots of ideological baggage. For many believers and theologians it is a red rag. Some of its racist and imperialist forms have been thoroughly discredited. For all those

10 Punt won't take orders from Nürnberger, the super-reader. Good for him! I did not realise my innocent book had such an oppressive impact on biblical scholars, or that it would "disempower both the Bible and biblical studies." I agree with him that gunsmiths are not supposed to be out hunting all day and that the hunter depends on the expertise of the gunsmith. If sensitivity against the traditional abuse of biblical texts by theologians, and their insistence on dogmatic correctness regardless of biblical evidence, lies behind his caustic and dismissive style, his frequent disregard for what I actually said, and his rather emotional outburst at the end, he has all my sympathies. I would only request him to give credit to the fact that I have worked myself into the world of Biblical scholarship (off and on over a whole decade), rather than imposing the classical loci of dogmatic theology onto the material of the canon. One does not do that if one holds a discipline in contempt.

11 Obviously, "streams of meaning" are not ontological entities independent of "theological construction" (Field), but theological construction happens within the process of the formation of collective consciousness that emerges and evolves over long periods of time. 
who think that meta-narratives have no right to exist, it is a no-no. But to me it has extraordinary explanatory power.

The problem is that the critics applied their own preconceived concepts of evolution to my work and judged it on this basis. Müller expected the manuscript to deal with the phylogenetic evolution of religious consciousness. Lawrie maintains that "evolutionary theory as such did not mediate these insights" and that I would have to "introduce a principle not inherent in evolutionary theory itself". Which evolutionary theory? In contrast to his otherwise empathetic reading of my book, Field perceives "a model developed in the natural sciences", one "described by physics", which (by definition?) implies linearity and progression and is, therefore, not applicable to biblical phenomena. Where I was referring to similarities between phenomena on various levels of emergence (biological and literary), Punt claims that I am "using biological procreation as a model", which "presupposes unmediated developments of meaning" and leads to "monolithic linearity".

The common verdict: I have imposed an extraneous, linear, stable, reductionist model on the phenomena and it just does not fit. But who has imposed what in this case? One could have expected that, in judging its adequacy, critics had operated with the concept of evolution as I had defined and utilised it. Here are a few characteristics:

1. The evolutionary process is marked by growth in complexity. As such, it is embedded in the cosmic entropic process leading from utmost concentration of energy (before the big bang) to utmost dissipation (at the end of time). Growth in complexity is growth in dissipation; construction depends on deconstruction. Radical deconstruction would be tantamount to the dissolution of all energy conglomerations, thus the end of reality as such. As a result, the life cycle of entities is characterised at each level by emergence, evolution, deterioration, and decay, except where low entropy energy is imported from the environment that is being deconstructed.

2. The process spans all dimensions of reality from micro-particles through inorganic matter, biological life, social conglomerations, patterns of collective consciousness, convictions, to visions. These dimensions of reality come into being through successive jumps in ascending levels of diversity, complexity, volatility, acceleration, and transience. Such a jump is called "emergence".

3. At each level the process branches out in a multitude of different streams that can compete, merge with other such streams, enter into symbiotic relationships, or reach dead ends. It is a highly integrated, dynamic system of relationships in which everything interacts with everything else (cf. the butterfly effect $=$ the impact of initial conditions in chaos theory).

I have defined evolution as this all-inclusive, constantly unfolding network of relationships and interactions, and used it with precisely this meaning in my trajectories. ${ }^{12}$ Here you find a host of roughly synchronic developments, symbiotic relationships, antagonistic relationships, and multi-directional causal relationships. I have shown the presence of progression as well as retrogression (as measured against the criterion of comprehensive well-being). I have highlighted evolution as well as entropic deterioration, construction as well as deconstruction. ${ }^{13}$ Progression of insight is claimed only in so far as redemptive

12 I have nothing at all against "intra- and intertextual dynamics" as suggested by Jonker. I have shown how both creation stories make contributions, as suggested by Field, and agree with his differentiation between gender and ecological issues in the two creation stories.

13 My approach includes and goes beyond Gerstenberger's plurality of theologies (cf Jonker). 
responses to genuine needs tend towards the achievement of well-being, and are ultimately lured into the direction of an ever changing vision of comprehensive well-being. ${ }^{14}$

So where exactly does the straight jacket begin to pinch? I have never claimed that the six trajectories that I traced cover the entire spectrum of biblical phenomena (cf Punt), or that one could not have pursued any number of tangents - as I have done in many instances. My trajectories were meant to blaze prototypical trails through a forest to give a sense of direction where the entire process seems to be heading. Could the critics at least concede that the six motifs I have chosen are pretty central to the biblical witness?

Of course, I could have left out the patriarchal paradigm. I could have added the paradigm of God's redemptive presence in his Spirit - which I have done in another context (Nürnberger 2002). I could have devoted a separate chapter to the paradigm of death and resurrection, which I treated as part of the covenant-law paradigm. I have also shown how these paradigms interact with each other. Nowhere did I seek to erect impenetrable boundaries or try to squeeze phenomena into contexts in which they do not belong. ${ }^{15}$

Surely my findings can be critiqued, augmented, corrected, refined, or shown to be unworkable. But I cannot be blamed for something that I never intended or attempted to do. As far as I am concerned, the reviewers have critiqued their own preconceptions at this point.

\section{Reductionism or Integration}

Again reductionism is a pervasive motif in the critique and closely linked to the above. According to Conradie, for instance, the enduring questions about the ultimate origin of the cosmos, though ultimately unanswerable, must be addressed. We need a theological cosmology. Indeed we do! But will this cosmology be based on the insights of two millennia ago or on current insights? The reviewer looked for traditional theological topics and did not find them in the new approach. A reductionist perception of an existing system of meaning can be corrected by adding missing aspects or elements. In a new system of meaning that is comprehensive and consistent, however, one can only develop dimensions or implications inherent in the new system that have not been articulated sufficiently. It is futile to look for wheels underneath a ship. Valid theological concerns are catered for in my proposal but in a new form.

Moreover, my theological system of meaning is more comprehensive, more integrated (cf Conradie) and more congruent with current secular insight than the traditional one. It is the traditional model that is reductionist. The idea that God completed the world and then rested (Gen 2:1ff; Heb 4:10), for instance, reduces God's creativity to a mythological beginning. The idea of providence reduces God's present creative activity to foresight or maintenance. The concept of creatio continua tried to correct these deficiencies, but the "once-and-for-all" idea persists among the faithful.

The theological consequences of this reductionism are considerable. While the mythological mode of thought projects what ought to be either to an ideal past (or an ideal future, or an ideal sphere above reality), an empiricist understanding of a perfect beginning suggests that the contemporary world as such is complete, which is simply wrong in terms

14 How can evolution account for inversion (Field)? It is the direct result of an evolutionary process geared to redemptive responses to genuine needs. The inverted paradigm is more in line with the comprehensiveness of well-being.

15 The only potential case I can think of is Is 53, which does not belong to the royal-imperial paradigm, but has impacted its further history decisively. 
of modern insight. The post-Enlightenment appropriation of this idea led to Deism, and further to the realisation that the God-hypothesis could be dispensed with altogether in a modern cosmology.

Traditional eschatology is equally reductionist. The integrated network of reality is taken apart into soul, body and world. The soul is catered for immediately after death, whether perceived as sleep, purgatory, or direct access to Christ. The body is left in limbo until resurrection happens some time in the future. The world continues as it is until it is transformed or replaced by God. In all three cases, humans can do absolutely nothing about it. The New Testament Naherwartung is abandoned. An ethic of anticipation of the kingdom ("already, but not yet") falters where the kingdom has become a never-never land.

In contrast, the new model is comprehensive and integrated. Unfolding (and collapsing) reality in all its manifold dimensions is the result of God's ongoing constructive (and deconstructive) activity. Nothing can happen without God's will; human wrongdoing, fateful developments in nature and society, suffering and death are powered by God's creativity. It is in this highly problematic realm that the Word of God is incarnate, which makes theological critique imperative. ${ }^{16}$

Likewise, God's redemptive vision encompasses the entire complex of unfolding (and collapsing) relationships within reality. It is perceived by us as a retreating horizon that is always tantalizingly close, thus again Naherwartung. It lures the faithful beyond the given situation towards untapped potentials, and beyond these potentials to the ever transcendent. ${ }^{17}$

\section{Transcendence or Pseudo-immanence}

Conradie finds a "denial of transcendence" in my work. Notably he suspects that I could do without the concept of a personal God altogether. It is true that I am trying to overcome notions of a sacred reality out there, whether perceived as essence (Plato), heaven above, a past paradise, or a future kingdom that is lying ready-made in waiting. Modern theology has long discovered that such objectifying conceptualisations do not yield transcendence, but a pseudo-immanence believed to be located elsewhere in the cosmos of God. My approach, in contrast, aims at true transcendence, based not on postulates, but on existential encounters with actual limitations.

1. The concept "Source of reality" (or God's mastery) transcends experienced reality "backward" in terms of the Source of its empowerment. There is a qualitative difference between a fountain and the stream flowing from it, but not a paradox, as in traditional theology.

16 Punt seems puzzled: "Does this in fact admit that divine response is mediated by (socially located) humans?" $\mathrm{O}$, dear! I have spent a whole chapter on arguing that divine action is mediated through earthly events and human agency, that it is subject to ambiguity, that critique is therefore necessary. I have claimed that human visualisations of the divine vision are highly diverse and in constant flux. I have shown in every trajectory that both needs and responses are sociologically and culturally conditioned, compromised by self-interest, ideological legitimation and error of judgment. How can Punt come to the conclusion that "truth appears to be a static, positivistic concept for Nürnberger, which creates havoc in his approach." Has he been reading another book?

17 How the vision of comprehensive well-being and its concrete manifestation in redemptive responses to changing needs in all dimensions of life can possibly show "how static and linear his understanding of soteriological paradigms is" (Jonker) is not clear. 
2. The concept "Destiny of reality" (or God's benevolence) transcends experienced reality "forward" in terms of what reality ought to be. God's eschatological vision defines what ought to be and lures reality in its direction, but he is not identical to it.

3. The concept of God as a person transcends human personhood and human relationality "upward" towards an Other in whose ultimate freedom and in whose ultimate responsibility we are invited to participate..$^{18} \mathrm{I}$ have put the spatial categories in inverted commas because they are metaphors.

The human response to transcendence is trust in a potential that goes beyond the capacity of the given; it is a protest against the limitations of the given in as far as they suppress life; it is an action pushing towards a closer approximation of what ought to be. It challenges us to seize what God can bring within our reach, and trust God's capacity to cater for what lies beyond our reach. Because it always envisions a response to actually felt needs and predicaments, it is infinitely flexible, and always immediate, just as its biblical antecedent.

I have determined the relationship between divine and human agency (cf Conradie) quite explicitly (p 10). Transcendence means that divine and human agency do not compete or cooperate on the same level. It is wrong to say that "either God or humans" act, or that "both God and humans act." God acts through human action. God's action does not obviate or supplement our action, but evokes and empowers it. God hardens Pharaohs heart, yet Pharaoh hardens his heart. Paul exhorts us: "Work out ... because it is God who is at work..." (Phil 2:12f). ${ }^{19}$

"How can divine agency in the world be understood if not on the basis of an outdated cosmology where a personal divine being intervenes in the laws of nature?" (Conradie) Answer: "God acts through the entire network (of causality), not only through extraordinary events which prompt bewilderment and awe" (p. 10). God is not a stopgap who intervenes in inner-worldly processes, but the Source and Destiny of the entire process, whether predictable or contingent. Because we are persons and because in faith we relate to God, God is for us a person, though for the cosmos as a whole he may be much more than a person.

\section{The Soteriological Basis of Theology}

Reductionism is also seen in the fact that I base theology on soteriological foundations, concretely on the need-response dialectic (cf Field, Conradie, Punt). To begin with: A particular point of departure does not have to preclude comprehensive theological horizons. Barth deduced his entire theological system from a single-sentence definition of God's selfrevelation. But a particular point of departure affects the character of the resultant theological system as a whole. Most basic is the question whether revelation concerns information on an alternative reality out there (whether to satisfy curiosity or to glorify God, whether gleaned from metaphysics or biblical statements), or the proclamation of God's redemptive intentions.

18 This is how "genuine human sovereignty" is distinguished from secular autonomy (Lawrie). It has nothing to do with selfishness per se.

19 Punt cannot understand how truth can be something that seeks us out, while still being our responsibility. Any conviction impresses its validity on our consciousness, or it is not a conviction, but just an opinion, or a hypothesis. Yet every conviction is our very own conviction. 
Luther belongs to the latter camp. He distinguished between God as such (Deus nudus) and God for us (Deus pro nobis). ${ }^{20}$ For him, "fides historica" (= the belief that something has happened in the past) was as useless a base for faith as metaphysical assumptions about a God in heaven. True faith was not assent to theological propositions, but trust in divine promise, and divine promise had a redemptive content. He distinguished between God's gracious self-disclosure through his Spirit and our "grabbing" in the form of metaphysics. He located God's glory in his condescension in Christ to suffer our woes (theologia crucis), rather than in his majesty (theologia gloriae).

I follow Luther in this respect because his theology makes it possible for us to do without metaphysical speculations and Biblicist assumptions, which is not the case if theology is perceived to be the development of extra-terrestrial or metaphysical information.

The critique is also rooted in a narrow concept of needs (cf Lawrie, Field). All human "concerns" signify the presence of needs. Psychologically, motivations are powered by needs such as ambition, alienation, cognitive dissonance, etc. Economically, supply responds to demand. We live in a reality intrinsically characterised by need. Construction presupposes deconstruction (thus dominance). Entropy implies disintegration (thus alienation) and dissipation (thus death, deterioration and, ultimately, the end of reality as a whole). This happens at all levels of emergence, including the communal and the spiritual. Spiritual needs are ultimately rooted in the "human condition" of dependence, vulnerability, and mortality. All religions are responses to this kind of predicament. I have dealt with three fundamental aspects of spiritual needs: Meaning, acceptability, and authority.

1. Meaning: The development of a cosmology, or an anthropology, however rudimentary, is itself a response to the need for a system of meaning, that is, a system of coordinates without which orientation would be impossible in an experienced ocean of total cosmic relativity.

2. Acceptability: The system of meaning includes perceptions of what is necessary to keep a particular life world from disintegrating, thus a system of values and norms. It formulates demands to respect these prerequisites of survival and well-being, punishes behaviour that threatens them, institutes rituals of restitution and reintegration (acceptability or right of existence).

3. Authority: The system of meaning defines concentric identities and allocates legitimate statuses and roles within the whole, always against the background of the prerequisites of life and prosperity. Spiritual needs thus include the entire spectrum of human consciousness. Which spiritual needs (cf Field) and which biblical themes (cf Conradie) cannot be accommodated in this analysis?

The normative aspect (what ought to be) that I call the "vision of God", is similarly comprehensive. Yet it is everything but vague (cf Lawrie, Punt). At any point in time it is concentrated on the most highly prioritised needs (deficiencies in comprehensive well-

20 In such a theology a theocentric focus cannot possibly be distinguished from an anthropocentric focus (cf Field) because theology deals with the relation between Creator and creature, between a graceful God and humanity in need of redemption, a God present in the community of believers, never with God as such or the human being as such. I agree with Punt that the Bible is "the deposit of people's interaction with God, the two-way responses ... all mediated by socially located humans". Idolatry (cf Field) is not accounted for by referring to a monotheistic postulate (which can in itself be idolatrous), but in non-conformity with the redemptive intentions of God in religious, psychological, social, economic, and political terms. Ideology as legitimation of self-interest at the expense of others is a prominent example. 
being): Leprosy, ostracism, inexplicable fate, or failure in an examination. Threshold theory deals with the fact that these priorities undergo constant changes.

If God is not a worldless entity up there, to which an isolated and bodiless soul can relate in mystical harmony, but the Source and Destiny of an integrated reality, which spiritual needs can be said not to be linked to immanent needs (cf Field)? The agonising questions which keep the biblical faith on its toes are generated not by disinterested forms of curiosity (though curiosity also expresses a need), nor by mystic longings (though longing also signifies a need), but by injustices, suffering, meaninglessness and death: Where is God? Who is God? What is he up to? When and where will it all end? What have I done wrong? This is the case even in Wisdom literature.

The need-response model cannot possibly "ignore the importance of negative experiences in shaping Israel's understanding of God and God's purposes..." (cf Field, Conradie, Punt). The negativity of experienced reality is precisely what the concepts of need and redemptive response are all about. But needs go far beyond what Israel experienced in terms of oppression, persecution, injustice, the failure of prophetic promises, and so on, simply because they are arise from the very fabric of reality, namely the evolutionary and entropic process as a whole as described above.

I have dealt with the negativity of experienced reality extensively and pervasively. The ecological problem, for instance, is tackled in the context of the sacrificial paradigm; theodicy in the context of the covenant-law paradigm; oppression in the contexts of the exodus-conquest and the royal-imperial paradigms, and so on.

\section{Anthropocentrism}

Reductionism is also seen in the perceived anthropocentrism of my approach (cf Field). Theology has always focused on the human being and I agree that it is time that the order be reversed: This tiny and insignificant creature should at last be seen where it belongs in the wide sweeps of cosmic time and space, at least in the context of myriads of other creatures on earth (Nürnberger 1999:374).

Seen in these total contexts, the need-response model is perfectly able to address nonanthropological issues such as the ecological crisis. Of course, we cannot play as if it were not humans who have such concerns. In the sense that needs are felt, interpreted, tackled or transcended by human individuals and groups, the (weak) anthropic principle of modern cosmology applies. Humans can only see reality through human eyes.

However, in line with the entire spectrum of levels of emergence, as sketched above, I have located the human need structure squarely in its concentric contexts: Spiritual needs must be seen in the context of the needs of the body, the community, society, humanity, the natural environment and the cosmos as a whole.

\section{The Need for Theology}

For me, the most fundamental question that has emerged out of this exercise, and that I think biblical scholars must answer for themselves, is whether we, as the church of Christ, need to develop a theology of the biblical witness and, by implication, a systematic theology at all. I have no doubt that we do. ${ }^{21}$

21 While another commentator testified that I reject all kinds of essentialism, for Punt (expressed in one of his insinuating questions) my "idealism" belongs to my "ideological baggage", which manifests itself in the fact that I am opting not for relativisation and cynicism but "to a renewed struggle for, and commitment to, the 
The task of the theologian is to try and establish at least some consistency, plausibility and relevance within the ambit of the Christian faith in the face of the near chaotic bunch of faith assumptions emanating from critical readings of the Bible, from spiritual readings found in ecumenical Christianity and from the wider pluralistic situation. Everything is in accelerating flux. There are those who can afford to enjoy the fling and there are those who are flung right out of the process.

Why not let nature take its course and accord equal dignity to the beautiful thistle and the useful potato plant? Because we live in the real world and have to face some brutal realities. If farmers the world over would accord equal dignity to thistles and potatoes, most of us would starve to death.

I have just seen the film "Hotel Rwanda". It depicts the genocide in one of the most Christianised countries in Africa. If the ethnic cleansing found in Deuteronomy 7 and the ethnic integration found in Ephesians 2 are to be accorded equal dignity and validity, may God help us! It is not the (re)construction of meta-narratives as such that present the greatest danger (cf Punt), but their absence, inappropriateness or ineffectiveness in terms of God's vision of comprehensive well-being.

The question whether we need theology or not is about the way we overcome the fetters and deceptions of modernity. At the same time, it is about the way we avoid the loose canons and deceptions of post-modern deconstructionism. I believe that true emancipation presupposes the growth of maturity of judgment and a sense of overarching responsibility. Freedom must be committed freedom, responsible freedom, communally based freedom. Where that is the agenda, I have no quarrel with post modernity. On the contrary, I am part of it. $^{22}$

But deconstruction without reconstruction is dangerous and irresponsible. In terms of evolutionary theory, it is spiritual entropy. ${ }^{23}$ It enhances the anomie caused by the pervasive and deliberate deconstruction of certainties and inhibitions by the advertising and entertainment industries for the sake of profit (analysed by Marx and Engels as early as the Communist Manifesto). It renders people without spiritual foundations defenceless against internal desire and external manipulation. Humanity simply cannot afford the uninhibited hedonism that drives us inexorably towards catastrophe.

\section{In Conclusion}

I would have loved to deconstruct some of the attempts of deconstructing my text, some of which I consider to be pure mischief making. ${ }^{24}$ I would have liked to point out the

truth". Punt's sensitivity against meta-narratives or "master-narratives" shows clearly at various points. The presumption is that we can and ought to do without them.

22 My casual references to postmodernism have indeed been too crude, but my critique is clearly focused on a trend within the movement and does not make the entire movement into a "scape goat for all that is

unacceptable" (Punt). For a more penetrating analysis of its role in economics, see Nürnberger 1999:221f.

23 Lakeland catches the mood rather well: postmodern sensibility "is characterised by cheerful ahistoricality, contented rootlessness, guiltless consumerism, and low expectations of the future" (1997:xiii). It is worth unpacking the immense consequences of each phrase. This general postmodern sensitivity should not be confused with the serious academic pursuits of people like Foucault and Derrida, though of course, there are linkages.

24 Punt, for instance, constantly pre-judges simple statements that I make: I claim, construe, relegate, impose, insist, grudgingly accept, admit, pull something out of the blue, say something unsurprising, feel compelled to, etc. He also takes statements out of context and constructs contradictions in my argument that make me look silly. 
problematic nature of some of their own assumptions and "grids". In some cases, I would have wished that my reviewers had read my work more carefully. Not that I blame them! Academics just do not have the leisure to study review literature with the same intensity, as they would read the theses of their doctoral students.

On the whole, I have not been persuaded by my critics that my project has failed. Hopefully that is not quite what they had wanted to say either. I am certain that my model is subtle, versatile, and inclusive; that it is more amenable to accelerating flux and situational diversity than conventional approaches; that it is more in line with modern insights, and thus better able to communicate the priceless gospel of Christ to our contemporaries. Far from claiming perfection, however, I am looking forward to a development, or an alternative, that outperforms its comprehensiveness, consistency and relevance in terms of contemporary insights and predicaments.

\section{BIBLIOGRAPHY}

Brueggemann, Walter 2002. Foreword. In: Nürnberger, Klaus 2002. Theology of the Biblical Witness: An evolutionary Approach. Muenster (Germany): LIT-Verlag, viiviii.

Lakeland, Paul 1997. Postmodernity. Christian identity in a fragmented age. Minneapolis: Fortress.

Nürnberger, Klaus 1991. Subscribing to confessional documents today. Journal of Theology for Southern Africa 75, June 1991, pp 37-47.

Nürnberger, Klaus 1999. Prosperity, poverty and pollution: Managing the approaching crisis. Pietermaritzburg: Cluster Publications/London: Zed Books.

Nürnberger, Klaus 2002. The Spirit of God: A soteriological metaphor in biblical history and its significance for us today. Scriptura, 79, 55-80.

Nürnberger, Klaus 2002. Theology of the Biblical Witness: An evolutionary Approach. Münster: LIT-Verlag.

Nürnberger, Klaus 2004. Biblical Theology in outline: The vitality of the Word of God. Pietermaritzburg: Cluster Publications/Pretoria: CB Powell Bible Centre.

Pre-publication assessments (unpublished)

Gerstenberger, Erhard (Old Testament, Marburg)

Rohloff, Juergen (New Testament, Erlangen)

Theissen, Gerhard (New Testament, Heidelberg)

West, Gerald (Old Testament, Pietermaritzburg)

Wittenberg, Gunter (Old Testament, Pietermaritzburg) 